\title{
Can I-124 PET/CT Predict Pathological Uptake of Therapeutic Dosages of Radioiodine (I-131) in Differentiated Thyroid Carcinoma?
}

\author{
Gauke K. Lammers ${ }^{1}$, Jan Paul Esser ${ }^{1}$, Pieternel C. M. Pasker ${ }^{2}$, \\ Marina E. Sanson-van Praag ${ }^{3}$, John M. H. de Klerk ${ }^{1}$ \\ ${ }^{1}$ Department of Nuclear Medicine, Meander Medical Centre, Amersfoort, The Netherlands \\ ${ }^{2}$ Department of Epidemiology and Research, Meander Medical Centre, Amersfoort, The Netherlands \\ ${ }^{3}$ Department of Internal Medicine, Meander Medical Centre, Amersfoort, The Netherlands \\ Email: ${ }^{*}$ gk.lammers@meandermc.nl, jp.esser@meandermc.nl, pcm.pasker@meandermc.nl, \\ me.sanson@meandermc.nl, jmh.de.klerk@meandermc.nl
}

Received 28 April 2014; revised 23 May 2014; accepted 18 June 2014

Copyright (C) 2014 by authors and Scientific Research Publishing Inc.

This work is licensed under the Creative Commons Attribution International License (CC BY). http://creativecommons.org/licenses/by/4.0/

(c) (i) Open Access

\section{Abstract}

Introduction: The aim of the study was to assess the role of I-124 PET/CT in the prediction of uptake of a therapeutic dosage I-131 during follow-up of patients with differentiated thyroid cancer (DTC). Methods: The results of 34 I-124 PET/CT scans performed in our hospital between 2007 and 2012 were retrospectively evaluated. All scans were made in patients under follow up, replacing the diagnostic I-131 or I-123 scintigraphy. In all cases thyroglobulin (Tg) was stimulated (by recombinant thyroid stimulating hormone (rhTSH) or thyroid hormone withdrawal). A dosage of $40 \mathrm{MBq}$ I-124 was used, with scans at 24 hours and 96 hours after administration. Results were compared to subsequent I-131 post-treatment scans ( 6 cases) and a combination of follow up, stimulated Tg and other imaging tools results available to assess presence of recurrence. Results: Recurrence of DTC was found in 14/34 cases. I-124 PET/CT correctly detected recurrence in 2 cases, with false negative results in 12 cases. In 1 case a false positive I-124 PET/CT result was recorded. 19 true negative results were found. For I-124 PET/CT this meant a sensitivity of 14\% and a specificity of $95 \%$. Positive predictive value was $67 \%$, negative predictive value $61 \%$. Posttreatment I-131 uptake (6 cases) was correctly predicted in 1 case, with false negative results in 4 cases and 1 true negative result. Conclusions: In this study I-124 PET/CT did not reliably detect recurrent differentiated thyroid carcinoma. More importantly it failed to predict I-131 uptake on post-treatment scintigraphy in a significant number of cases, which would lead to under-treatment.

\footnotetext{
*Corresponding author.
}

How to cite this paper: Lammers, G.K., Esser, J.P., Pasker, P.C.M., Sanson-van Praag, M.E. and de Klerk, J.M.H. (2014) Can I-124 PET/CT Predict Pathological Uptake of Therapeutic Dosages of Radioiodine (I-131) in Differentiated Thyroid Carcinoma? Advances in Molecular Imaging, 4, 27-34. http://dx.doi.org/10.4236/ami.2014.43004 


\section{Keywords}

\section{I-124, PET, I-131, Thyroid, Carcinoma}

\section{Introduction}

Differentiated thyroid carcinoma (DTC) generally has a good outcome, when treated with a combination of a total thyroidectomy, followed by an iodine-131 (I-131) ablation therapy. However, recurrences do occur and may still do so many years after initial treatment. Patients are therefore enrolled in a long-time follow-up regimen. The intensity of the regimen is based on a risk profile, consisting of primary tumour characteristics, evidence of metastases and patient age. The detection of recurrence is mainly based on monitoring of serum thyroglobulin (Tg) levels, which reflect the presence of remaining thyroid tissue or DTC cells in the body in a sensitive way. Also, a combination of routine physical exam and imaging techniques such as ultrasonography of the neck is common practice. However, even with significantly elevated Tg levels, metastatic disease is not always detected by conventional imaging techniques or diagnostic (tracer amount) I-131 or I-123 whole body scintigraphy (WBS) [1]-[6]. When recurrence of DTC is suspected (elevated levels of Tg) and all other diagnostic modalities are negative, it currently is common practice to give I-131 therapy ("blind" or empiric therapeutic dosage). This therapy also serves a diagnostic purpose, by allowing assessment of the extent of disease on subsequent whole body scintigraphy.

Unfortunately, after this so called "blind” I-131 therapy, there is no visible I-131 uptake on post-treatment scintigraphy in a significant number of patients [7] [8]. This means that these patients might have no benefit of I-131 therapy, because there is no I-131 uptake in (suspected) tumorous tissue. The challenge is to find a means to prevent this unnecessary I-131 treatment. Diagnostic (tracer amount) I-131 or I-123 whole body scintigraphy should in theory predict iodine uptake, but it is not always reliable [1]-[3]. Fluorodeoxyglucose (FDG) positron emission tomography with computer tomography (PET/CT) has a prominent role in oncology nowadays and can provide useful information about tumour metabolic rate. Although FDG uptake has been reported to be inversely related to iodine uptake ("flip-flop" phenomenon) [9] [10], it does not seem to be practical tool in predicting iodine uptake. A truly promising tool for identifying patients who will benefit from I-131 therapy is I-124 PET/ CT, which should predict the uptake of a therapeutic dosage of I-131.

I-124 PET/CT could therefore be important in personalizing treatment for patients with DTC. A number of promising reports that show the diagnostic potential of I-124 PET/CT have been published [11]-[14]. I-124 PET/CT is increasingly being used in follow up of DTC and has been used in our hospital since 2007, replacing the diagnostic (tracer amount) I-131 scintigraphy. We retrospectively assessed the potential added value of I-124 $\mathrm{PET} / \mathrm{CT}$ in our hospital.

\section{Methods}

\subsection{Patients}

We included all patients ( $\mathrm{n}=30,23$ females, 7 males), average age 54 y (range $17-77$ y) with DTC who had undergone at least one I-124 PET/CT from 2007 to 2012. Eight patients had follicular thyroid carcinoma, 21 patients had papillary carcinoma and one patient had Hürthle cell type carcinoma. I-124 PET/CT was performed during follow up and at least 6 months after initial surgical and I-131 ablation therapy. No specific further selections were made. The study has been approved by the institutional review board.

\subsection{Patient Preparation}

All PET/CTs were made under adequate stimulation by high thyroid stimulating hormone (TSH) levels (the lowest TSH was $47 \mathrm{mIU} / \mathrm{L}$, average TSH was 82 (when result: >100 was considered as 100)) by either recombinant human thyrotropin (rhTSH) or thyroid hormone withdrawal. Stimulated serum Tg, anti-Tg and TSH levels were recorded from samples taken both the day of the I-124 PET/CT scan and the day before. The maximum levels of both samples were recorded. Tg and anti-Tg were measured with an electrochemiluminescence immunoassay (ECLIA) on a Roche Cobas ${ }^{\circledR} 6000$ analyzer, with a detection limit of $0.15 \mathrm{pmol} / \mathrm{L}$ for Tg. 


\subsection{PET Scanning and Tracer}

PET/CT scans were made on a Siemens Biograph Truepoint ${ }^{\mathrm{TM}} 40$ PET/CT scanner and combined with low dose CT for attenuation correction and anatomical localisation. A standard dose of $40 \mathrm{MBq}$ I-124 was used intravenously. Scans at 24 hours and 96 hours post injection were obtained. Scans were made from the upper thighs to the top of the head. An acquisition time of 5 minutes per bed position was used, with iterative 3D reconstruction by four iterations with 8 subsets and a Gaussian filter. The low dose CT was made with 120 kV, 30 mAs (reference, Siemens CARE Dose4D ${ }^{\mathrm{TM}}$ automatic exposure control), pitch $0.8 \mathrm{~mm}$ and 0.5 s rotation time.

\subsection{Data Analysis}

PET/CTs ( $\mathrm{n}=34$, in 30 patients) were visually evaluated by 2 well experienced nuclear physicians. A positive I-124 PET/CT scan was defined as having a visually abnormal uptake, with no other likely explanation but recurrence of DTC. A negative I-124 PET/CT was defined as having a visually normal distribution of activity. The I-124 PET/CT results were compared with I-131 therapy whole body scintigraphy if available. I-131 scintigraphy was done 7 days after treatment. Therapy dosages ranged from $3700 \mathrm{MBq}(100 \mathrm{mCi})$ to $7400 \mathrm{MBq}$ (200 mCi). A positive I-131 scintigraphy was defined as having a visually abnormal uptake of activity, with no other likely explanation but DTC. The I-124 PET/CT results were also compared with histological results when available, stimulated serum Tg levels (positive defined as $>3 \mathrm{pmol} / \mathrm{L}$ ( $>2 \mathrm{ng} / \mathrm{mL}$ ), with no detectable anti-Tg), and other means of imaging techniques such as FDG-PET/CT, CT, MRI and ultrasonography. Recurrence of DTC was defined as any combination of results showing (suspected) recurrence, provided this was within a timeslot of no longer than 4 months prior to or after the I-124 PET/CT.

A database of results was created on a per patient basis (The essential information is shown in Table 1). Sensitivity, specificity, positive predictive value and negative predictive value of I-124 PET/CT were calculated using a conventional $2 \times 2$ table comparing the I-124 PET/CT result to the presence of recurrence (Table 2 ). A $2 \times$ 2 table was also used comparing I-124 PET-CT to the post therapy I-131 WBS (Table 3).

\section{Results}

Recurrence of DTC was found in 14/34 cases. I-124 PET/CT correctly detected recurrence in 2/14 cases, with false negative results in 12 cases. In 1 case a false positive I-124 PET/CT result was recorded. 19 true negative I-124 PET-CT results were found. Thus, the sensitivity of I-124 PET/CT was 14\% and the specificity 95\%. positive predictive value was 67\%, negative predictive value 61\%. These findings are illustrated by Table 2.

In six of 14 cases with recurrence of DTC, subsequent I-131 therapy was given. In two of these six cases I-131 uptake was correctly predicted by I-124 PET/CT (in one case there was no sign of I-131 or I-124 uptake). In four cases I-124 PET/CT was false negative. These findings are illustrated by Table 3. Figure 1 shows example images of a false negative case.

The results on a per patient basis are summarized in Table 1 . In 11 cases not all information about staging could be retrieved. In two patients significant anti-Tg was present (patient nr. 14 and 15), meaning reliable Tg measurement was impossible. Lacking other evidence of disease, and showing a downward trend of anti-Tg in follow-up (in one case even normalization of anti-Tg and Tg levels), these two patients were considered as having no recurrence. In one case (patient nr. 2) there was a skull lesion on I-124 PET/CT, with no sign of recurrence based on Tg, CT and MRI. This lesion was also visible on initial post-ablation I-131 WBS six months earlier. The reason of this iodine uptake is unclear up to this moment. We considered this I-124 PET/CT as true positive.

\section{Discussion}

Our results showed that in only a few cases (two out of 14) I-124 PET/CT was able to detect recurrence of DTC. However, the most important finding was that I-124 PET/CT could not predict post treatment I-131 uptake adequately, with four false negative results out of six cases. If the decision of I-131 therapy had been based solely on I-124 PET/CT results of these patients, these four patients would have been withheld an effective therapy. This finding seems to contradict earlier studies with more positive results, but these comparisons between I-124 PET (with or without CT) and I-131 therapy have mostly been done in the pre-therapeutic phase, not in the follow-up phase [11] [15]. Some studies have been published about the role of I-124 PET in the follow-up phase. We will discuss them below. 
Table 1. Patient and tumour characteristics, test results and supplementary information.

\begin{tabular}{|c|c|c|c|c|c|c|c|c|c|c|}
\hline $\mathrm{Nr}$ & Sex/age ${ }^{a}$ & Type $^{\text {b }}$ & TNM & $\mathrm{Rh}-\mathrm{TSH}^{\mathrm{c}}$ & $\mathrm{TSH}^{\mathrm{d}}$ & $\operatorname{Tg}^{\mathrm{e}}$ & $\begin{array}{c}\mathrm{I}-124 \\
\mathrm{PET}^{-} \mathrm{CT}^{\mathrm{f}}\end{array}$ & $\begin{array}{l}\text { Posttx } \\
\text { I-131 WBS }\end{array}$ & $\begin{array}{l}\text { Other } \\
\text { imaging }^{\text {h }}\end{array}$ & Comment/validation \\
\hline 1 & $\mathrm{~F} / 21$ & Pap & T4N1M1 & $\mathrm{y}$ & $>100$ & 66 & $\begin{array}{c}\mathrm{TP} \\
\text { (lung) }\end{array}$ & $+(200 \mathrm{mCi})$ & $\mathrm{CT}+$ & Lung metastases on CT \\
\hline 2 & $\mathrm{M} / 29$ & Pap & T1/2N0M0 & $\mathrm{y}$ & $>100$ & 0.3 & $\mathrm{TP}$ & $\mathrm{n} / \mathrm{a}$ & CT/MRI- & $\begin{array}{c}\text { I-124 + lesion skull, earlier } \\
\text { post-ablation I-131 + (100 mCi), } \\
\text { normal CT and MRI. } \\
\text { No substrate on CT/MRI }\end{array}$ \\
\hline 3 & $\mathrm{~F} / 44$ & Pap & T1N0M0 & $\mathrm{y}$ & $>100$ & $<0.2$ & FP & $\mathrm{n} / \mathrm{a}$ & $\mathrm{CT}-$ & $\begin{array}{l}\text { Cricoid activity, } \\
\text { no substrate on CT }\end{array}$ \\
\hline \multirow[t]{2}{*}{4} & $\mathrm{M} / 60$ & Pap & T3N1M0 & $\mathrm{y}$ & 89 & 36 & $\mathrm{FN}$ & $+(200 \mathrm{mCi})$ & $\mathrm{FDG}^{+}$ & Lymph nodes mediastinum \\
\hline & $\mathrm{M} / 61$ & Pap & T3N1M0 & $\mathrm{n}$ & 69 & 71 & $\mathrm{FN}$ & $+(200 \mathrm{mCi})$ & $\mathrm{FDG}^{+}$ & Lymph nodes mediastinum \\
\hline 5 & $\mathrm{~F} / 17$ & Pap & T4N1M0 & $\mathrm{n}$ & $>100$ & 1182 & $\mathrm{FN}$ & $+(150 \mathrm{mCi})$ & $\mathrm{FDG}^{+}$ & Lymph nodes neck \\
\hline 7 & $\mathrm{~F} / 57$ & Fol & T3N0M1 & $\mathrm{y}$ & 49 & 4706 & $\mathrm{FN}$ & $+(200 \mathrm{mCi})$ & $\mathrm{FDG}^{+}$ & Multiple bone metastases \\
\hline 8 & M/35 & Pap & T?N1M0 & $\mathrm{y}$ & 72 & 28 & $\mathrm{FN} / \mathrm{TN}^{*}$ & $-(150 \mathrm{mCi})$ & $\mathrm{n} / \mathrm{a}$ & $\begin{array}{l}\text { * I-124 was false negative } \\
\text { based on Tg, but was } \\
\text { concordant with } \\
\text { post therapy I-131 WBS }\end{array}$ \\
\hline & $\mathrm{M} / 46$ & Pap & T?N1M0 & $\mathrm{n}$ & 82 & 14 & FN & $\mathrm{n} / \mathrm{a}$ & US neck- & $\begin{array}{l}\text { Based on elevated Tg, } \\
\text { now watchful waiting }\end{array}$ \\
\hline 9 & $\mathrm{M} / 61$ & Hür & T4N?M0 & $\mathrm{y}$ & 73 & 1387 & FN & $\mathrm{n} / \mathrm{a}$ & $\begin{array}{l}\text { Octreoscan+, } \\
\text { CT- }\end{array}$ & $\begin{array}{l}\text { Lung/lymph node metastases } \\
\text { I-131 negative. Earlier } \\
\text { post therapy I-131 negative. }\end{array}$ \\
\hline 10 & $\mathrm{~F} / 71$ & Pap + Fol & T2N0M1 & $\mathrm{y}$ & $>100$ & 3 & $\mathrm{TN}$ & $\mathrm{n} / \mathrm{a}$ & $\mathrm{n} / \mathrm{a}$ & \\
\hline 11 & $\mathrm{~F} / 31$ & Pap & T3N1M0 & $\mathrm{y}$ & $>100$ & 38 & $\mathrm{FN}$ & $\mathrm{n} / \mathrm{a}$ & $\mathrm{FDG}^{+}$ & $\begin{array}{c}\text { Lymph nodes } \\
\text { neck/mediastinum. Surgery }\end{array}$ \\
\hline 12 & $\mathrm{~F} / 22$ & Pap & T2N1M0 & $\mathrm{y}$ & 47 & 6 & FN & $\mathrm{n} / \mathrm{a}$ & US neck- & $\begin{array}{l}\text { Based on elevated Tg, } \\
\text { watchful waiting }\end{array}$ \\
\hline 13 & $\mathrm{M} / 44$ & Pap & T?N1M0 & $\mathrm{y}$ & 64 & 11 & FN & $\mathrm{n} / \mathrm{a}$ & US neck- & $\begin{array}{l}\text { Based on elevated Tg, } \\
\text { watchful waiting }\end{array}$ \\
\hline 14 & $\mathrm{~F} / 56$ & Fol & T2N0M0 & $\mathrm{y}$ & $>100$ & $\begin{array}{c}* \text { anti-Tg } \\
165\end{array}$ & $\mathrm{TN}$ & $\mathrm{n} / \mathrm{a}$ & FDG- & $\begin{array}{l}\text { Stimulated Tg and Anti-Tg } \\
\text { negative on follow up } \\
1 \text { year later with normal } \\
\text { FDG/i-124 PET }\end{array}$ \\
\hline \multirow[t]{2}{*}{15} & $\mathrm{~F} / 63$ & Pap & T?N1M0 & $\mathrm{y}$ & $>100$ & $\begin{array}{c}* \text { anti-Tg } \\
219\end{array}$ & $\mathrm{TN}$ & $\mathrm{n} / \mathrm{a}$ & $\mathrm{FDG}^{+}(\mathrm{FP})$ & $\begin{array}{l}\text { FDG avid lesion not found in sur- } \\
\text { gery. Anti-Tg positive }\end{array}$ \\
\hline & $\mathrm{F} / 65$ & Pap & T?N1M0 & $\mathrm{y}$ & $>100$ & $\begin{array}{c}* \text { anti-Tg } \\
164\end{array}$ & $\mathrm{TN}$ & $\mathrm{n} / \mathrm{a}$ & $\mathrm{n} / \mathrm{a}$ & $\begin{array}{c}\text { I-124 considered TN } \\
\text { because of lowered anti-Tg }\end{array}$ \\
\hline 16 & F/33 & Pap + Fol & T2N0M0 & $\mathrm{y}$ & 94 & $<0.2$ & $\mathrm{TN}$ & $\mathrm{n} / \mathrm{a}$ & $\mathrm{n} / \mathrm{a}$ & \\
\hline 17 & $\mathrm{~F} / 51$ & Fol & T1N?M? & $\mathrm{y}$ & 95 & 0.4 & $\mathrm{TN}$ & $\mathrm{n} / \mathrm{a}$ & $\mathrm{n} / \mathrm{a}$ & \\
\hline 18 & $\mathrm{~F} / 63$ & Pap & T?N1M0 & $\mathrm{y}$ & $>100$ & 0.4 & $\mathrm{TN}$ & $\mathrm{n} / \mathrm{a}$ & $\mathrm{FDG}^{-}$ & \\
\hline 19 & $\mathrm{~F} / 60$ & Fol - Hür & T2N0M0 & $\mathrm{y}$ & $>100$ & $<0.2$ & $\mathrm{TN}$ & $\mathrm{n} / \mathrm{a}$ & US neck- & \\
\hline 20 & F/39 & Pap & T4N1M0 & $\mathrm{y}$ & 90 & $<0.2$ & $\mathrm{TN}$ & $\mathrm{n} / \mathrm{a}$ & US nec- & \\
\hline 21 & $\mathrm{~F} / 67$ & Pap & T2N0M0 & $\mathrm{y}$ & $>100$ & $<0.2$ & $\mathrm{TN}$ & $\mathrm{n} / \mathrm{a}$ & US neck- & \\
\hline
\end{tabular}




\section{Continued}

\begin{tabular}{|c|c|c|c|c|c|c|c|c|c|}
\hline 22 & $\mathrm{~F} / 55$ & Рap & T2N1M0 & $\mathrm{y}$ & 48 & 2 & $\mathrm{TN}$ & $\mathrm{n} / \mathrm{a}$ & US neck- \\
\hline 23 & $\mathrm{~F} / 27$ & Рap & T1N1M0 & $\mathrm{n}$ & 63 & 2 & $\mathrm{TN}$ & $\mathrm{n} / \mathrm{a}$ & $\mathrm{FDG}^{-}$ \\
\hline 24 & $\mathrm{~F} / 59$ & Fol & T?N?M? & $\mathrm{y}$ & $>100$ & $<0.2$ & $\mathrm{TN}$ & $\mathrm{n} / \mathrm{a}$ & FDG- \\
\hline 25 & $\mathrm{~F} / 43$ & Рар & T?N1M0 & $\mathrm{y}$ & $>100$ & 0.4 & $\mathrm{TN}$ & $\mathrm{n} / \mathrm{a}$ & FDG $^{-}$ \\
\hline 26 & $\mathrm{~F} / 56$ & Рар & T?N0M0 & $\mathrm{n}$ & 89 & 0.2 & $\mathrm{TN}$ & $\mathrm{n} / \mathrm{a}$ & FDG- \\
\hline 27 & $\mathrm{~F} / 46$ & Рap & T1N1M0 & $\mathrm{y}$ & $>100$ & $<0.2$ & $\mathrm{TN}$ & $\mathrm{n} / \mathrm{a}$ & US neck- \\
\hline 28 & $\mathrm{~F} / 43$ & Fol & T1N0M0 & $\mathrm{y}$ & 51 & $<0.2$ & $\mathrm{TN}$ & $\mathrm{n} / \mathrm{a}$ & FDG- \\
\hline 29 & $\mathrm{M} / 77$ & Fol & T3N0M0 & $\mathrm{y}$ & $>100$ & $<0.2$ & $\mathrm{TN}$ & $\mathrm{n} / \mathrm{a}$ & FDG- \\
\hline 30 & $\mathrm{~F} / 65$ & Pap & T2N0M0 & $\mathrm{n}$ & 69 & $<0.2$ & $\mathrm{TN}$ & $\mathrm{n} / \mathrm{a}$ & US neck- \\
\hline
\end{tabular}

${ }^{\mathrm{a}} \mathrm{F}$ = female, $\mathrm{M}$ = male, age is in years; ${ }^{\mathrm{b}} \mathrm{Pap}=$ papillary carcinoma, Fol = follicular carcinoma, Hür = Hürthle cell carcinoma; ${ }^{\mathrm{c}} \mathrm{y}=\mathrm{rhTSH}, \mathrm{n}=$ thyroid hormone withdrawal; ${ }^{\mathrm{d}} \mathrm{TSH}$ is in $\mathrm{mIU} / \mathrm{L}$; ${ }^{\mathrm{e}} \mathrm{Tgis}$ in $\mathrm{pmol} / \mathrm{L} ;{ }^{\mathrm{f}} \mathrm{TP}=$ true positive, $\mathrm{FP}=$ false positive, $\mathrm{TN}$ = true negative, $\mathrm{FN}$ = false negative; ${ }^{\mathrm{g}}$ posttx I-131 = post therapy I-131 WBS; ${ }^{\mathrm{h}_{+}}=$positive, $-=$negative, $\mathrm{n} / \mathrm{a}=$ not available.
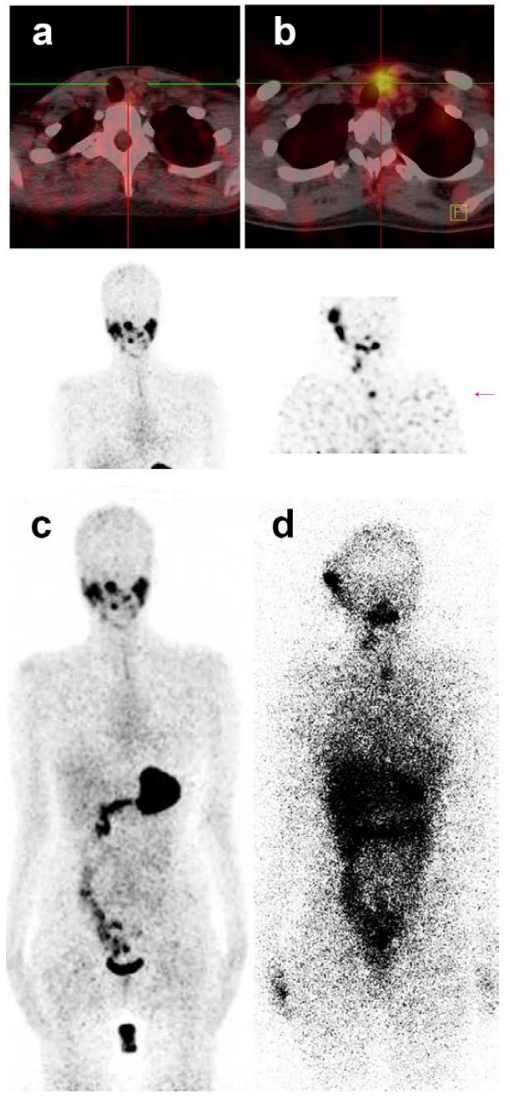

Figure 1. Example of false negative I-124 PET/CT (patient nr 5, Table 1). (a) Shows a transverse fused I-124 PET/CT image (24 hours after administration) and below that the corresponding maximum intensity projection (MIP) showing no pathological uptake; (b) Shows the post treatment I-131 fused SPECT/ CT image at the same level, again with corresponding MIP below. The I-131 image shows markedly increased uptake in a lymph node in the upper mediastinum and in lymph nodes in the neck (right side); (c) Shows the I-124 MIP with normal distribution of activity; (d) Is the post treatment I-131 WBS, again with the I-131 positive neck and mediastinal lymph nodes (note: there is contamination around the right ear and hand in the I-131 images). 
Table 2. $2 \times 2$ table of I-124 PET/CT results compared with presence of recurrence.

\begin{tabular}{ccc}
\hline Table Head & Recurrence & No recurrence \\
\hline I-124 positive & 2 & 1 \\
I-124 negative & 12 & 19 \\
\hline
\end{tabular}

Table 3. $2 \times 2$ table of I-124 PET/CT results compared with I-131 post therapy WBS outcome.

\begin{tabular}{ccc}
\hline Table Head & I-131 positive & I-131 negative \\
\hline I-124 positive & 1 & 0 \\
I-124 negative & 4 & 1 \\
\hline
\end{tabular}

Phan et al. [12] found an I-124 PET (PET only) to predict post treatment I-131 uptake adequately in patients under follow up. Out of 20 patients with histologically proven advanced DTC, 11 had a positive I-124 PET. Nine of these 11 patients showed I-131 uptake. However, they also found two false positive and two false negative I-124 PETs, in which post-treatment I-131 WBS was positive.

Lee et al. [14] found a good performance of FDG-PET/CT and I-124 PET/CT combined in a prospective study in 19 patients with DTC under follow up with elevated Tg levels (stimulated) and negative ultrasound and diagnostic I-131 WBS. Treatment strategy was changed in 6/19 patients. However, 6 negative I-124 PET/CTs were found in patients with recurrence correctly identified by FDG-PET/CT. Conversely, in the 4 true-positive I-124 PET/CTs, FDG-PET/CT was negative. This suggests a complementary performance of FDG and I-124PET/CT, which is in line with the known "flip-flop" phenomenon in which DTC loses the ability to take up iodine and takes up more FDG. Unfortunately no comparison with subsequent post I-131 therapy WBS results was published.

A similar study was done by Freudenberg et al. [16] who also showed a good sensitivity of I-124 PET/CT and FDG-PET combined. The sensitivity of I-124 PET/CT alone was 49\%. No comparison with post therapy I-131 WBS was made.

We do not have a clear explanation for our conflicting results of I-124 PET/CT. Possible factors include (a combination of):

1) Difference in patient preparation between our study and earlier studies. Although in our study average TSH was at least comparable with the other studies, there are some differences. Lee et al. [14] used 4 weeks of levothyroxine withdrawal for stimulation and a low-iodine diet. Freudenberg et al. [16] also mainly used levothyroxine withdrawal for at least 4 weeks, but no low-iodine diet. Phan et al. [12] used both rhTSH and levothyroxine withdrawal but they did not specify this further. In our study we primarily used rhTSH (28/34 scans) and no low-iodine diet.

2) Different timing of scanning. I-131 post therapy scans are made at 7 days after administration, versus I-124 PET/CT at 24 hours and 96 hours after administration. Although most iodine will be in target regions within 24 hours, during the following days target to background ratios may improve in I-131 scanning with its longer halflife of 8 days. I-124 PET/CT has a shorter half-life of 4.2 days, which may cause a worse signal to noise ratio at even 96 hours after administration. We did consistently find poor signal intensity at 96 hours after administration, supporting this theory.

3) Pharmacological dosage dependent difference. $40 \mathrm{MBq}$ of I-124 equates to $3.5 \times 10^{-11}$ mol of iodine atoms, whereas a typical I-131 therapeutic dosage of $5550 \mathrm{MBq}$ equates to $9.2 \times 10^{-9}$ mol of iodine atoms, which is about 263 times as much. In theory this might cause a different tracer distribution in the body. There is not yet a standardized dosage protocol for I-124 PET. Some studies use a higher dosage I-124 (about $74 \mathrm{MBq}$ ), instead of $40 \mathrm{MBq}$ [12]-[14], On the other hand, a dosage of $20 \mathrm{MBq}$ has also been used with good results [17] [18]. Now, we suggest using a minimum of $74 \mathrm{MBq}$ I-124 for further research and in daily practice to minimise the influence of the administered dose.

4) Factors like scanner malfunction, tracer quality problems. This seems unlikely, because we have found no indications for these types of problems and there are positive I-124 PET/CTs. 
Although not designed for this purpose, the results of our study may have implications for the use of I-124 $\mathrm{PET} / \mathrm{CT}$ in dosage calculation. Earlier studies have shown that I-131 dosage calculation at least in pre-therapeutic setting, is feasible with I-124 PET/CT [19]-[21]. Our results do show I-124 uptake in some patients, corresponding with I-131 uptake on post therapy WBS. In this way our study shows that dosage calculation in follow up should be possible, however, the false negative I-24 PET/CT results indicate that one should take into account that a negative I-124 PET/CT does not rule out I-131 uptake.

Since this is a relatively small retrospective study, further investigations are necessary. We expect more definitive recommendations about I-124 PET/CT in follow up of DTC can be made when the now open multicentre prospectively designed THYROPET study is completed.

\section{Conclusion}

In this study I-124 PET/CT did not reliably detect recurrent differentiated thyroid carcinoma. More disappointingly, it failed to predict I-131 uptake on post-treatment scintigraphy in a significant number of cases. This would lead to under-treatment if I-124 PET/CT would be used for treatment decisions regarding I-131 therapy. We have not found a clear explanation for these conflicting results. Possible factors include differences in patient preparation, timing of scanning after tracer administration and dosage related factors. At this time we cannot recommend I-124 PET/CT as a tool to predict I-131 uptake. The role of I-124 PET/CT in the follow up of DTC seems limited. Since this is a small, single centre study, further investigations are necessary. Further studies to define the definite role of I-124 PET/CT are underway (THYROPET study).

\section{References}

[1] Verburg, F.A., de Keizer, B., de Klerk, J.M., Lentjes, E.G., Lips, C.J. and van Isselt, J.W. (2009) Value of Diagnostic Radioiodine Scintigraphy and Thyroglobulin Measurements after rhTSH Injection. Nuklearmedizin, 48, 26-29.

[2] de Meer, S.G., Vriens, M.R., Zelissen, P.M., BorelRinkes, I.H. and de Keizer, B. (2011) The Role of Routine Diagnostic Radioiodine Whole-Body Scintigraphy in Patients with High-Risk Differentiated Thyroid Cancer. Journal of Nuclear Medicine, 52, 56-59. http://dx.doi.org/10.2967/jnumed.110.080697

[3] Torlontano, M., Crocetti, U., D’Aloiso, L., Bonfitto, N., Di Giorgio, A., Modoni, S., Valle, G., Frusciante, V., Bisceglia, M., Filetti, S., et al. (2003) Serum Thyroglobulin and 131I Whole Body Scan after Recombinant Human TSH Stimulation in the Follow-Up of Low-Risk Patients with Differentiated Thyroid Cancer. European Journal of Endocrinology/European Federation of Endocrine Societies, 148, 19-24.

[4] Anderson, G.S., Fish, S., Nakhoda, K., Zhuang, H., Alavi, A. and Mandel, S.J. (2003) Comparison of I-123 and I-131 for Whole-Body Imaging after Stimulation by Recombinant Human Thyrotropin: A Preliminary Report. Clinical $\mathrm{Nu}$ clear Medicine, 28, 93-96. http://dx.doi.org/10.1097/01.RLU.0000048678.96894.9A

[5] Iwano, S., Kato, K., Nihashi, T., Ito, S., Tachi, Y. and Naganawa, S. (2009) Comparisons of I-123 Diagnostic and I-131 Post-Treatment Scans for Detecting Residual Thyroid Tissue and Metastases of Differentiated Thyroid Cancer. Annals of Nuclear Medicine, 23, 777-782. http://dx.doi.org/10.1007/s12149-009-0303-z

[6] Alzahrani, A.S., AlShaikh, O., Tuli, M., Al-Sugair, A., Alamawi, R. and Al-Rasheed, M.M. (2012) Diagnostic Value of Recombinant Human Thyrotropin-Stimulated (1)(2)(3)I Whole-Body Scintigraphy in the Follow-Up of Patients with Differentiated Thyroid Cancer. Clinical Nuclear Medicine, 37, 229-234. http://dx.doi.org/10.1097/RLU.0b013e31823ea463

[7] van Tol, K.M., Jager, P.L., de Vries, E.G., Piers, D.A., Boezen, H.M., Sluiter, W.J., Dullaart, R.P. and Links, T.P. (2003) Outcome in Patients with Differentiated Thyroid Cancer with Negative Diagnostic Whole-Body Scanning and Detectable Stimulated Thyroglobulin. European Journal of Endocrinology/European Federation of Endocrine Societies, 148, 589-596.

[8] Ma, C., Xie, J. and Kuang, A. (2005) Is Empiric 131I Therapy Justified for Patients with Positive Thyroglobulin and Negative 131I Whole-Body Scanning Results? Journal of Nuclear Medicine, 46, 1164-1170.

[9] Feine, U., Lietzenmayer, R., Hanke, J.P., Wohrle, H. and Muller-Schauenburg, W. (1995) [18FDG Whole-Body PET in Differentiated Thyroid Carcinoma. Flipflop in Uptake Patterns of 18FDG and 131I]. Nuklearmedizin, 34, 127-134.

[10] McDougall, I.R., Davidson, J. and Segall, G.M. (2001) Positron Emission Tomography of the Thyroid, with an Emphasis on Thyroid Cancer. Nuclear Medicine Communications, 22, 485-492. http://dx.doi.org/10.1097/00006231-200105000-00004

[11] Freudenberg, L.S., Antoch, G., Jentzen, W., Pink, R., Knust, J., Gorges, R., Muller, S.P., Bockisch, A., Debatin, J.F. and Brandau, W. (2004) Value of (124)I-PET/CT in Staging of Patients with Differentiated Thyroid Cancer. European 
Radiology, 14, 2092-2098. http://dx.doi.org/10.1007/s00330-004-2350-0

[12] Phan, H.T., Jager, P.L., Paans, A.M., Plukker, J.T., Sturkenboom, M.G., Sluiter, W.J., Wolffenbuttel, B.H., Dierckx, R.A. and Links, T.P. (2008) The Diagnostic Value of 124I-PET in Patients with Differentiated Thyroid Cancer. European Journal of Nuclear Medicine and Molecular Imaging, 35, 958-965. http://dx.doi.org/10.1007/s00259-007-0660-6

[13] Van, N.D., Moreau, S., Bandaru, V.V., Atkins, F., Chennupati, S., Mete, M., Burman, K. and Wartofsky, L. (2010) (124)I Positron Emission Tomography versus (131)I Planar Imaging in the Identification of Residual Thyroid Tissue and/or Metastasis in Patients Who Have Well-Differentiated Thyroid Cancer. Thyroid, 20, 879-883. http://dx.doi.org/10.1089/thy.2009.0430

[14] Lee, J., Nah, K.Y., Kim, R.M., Oh, Y.J., An, Y.S., Yoon, J.K., An, G.I., Choi, T.H., Cheon, G.J., Soh, E.Y. and Chung, W.Y. (2012) Effectiveness of [(124)I]-PET/CT and [(18)F]-FDG-PET/CT for Localizing Recurrence in Patients with Differentiated Thyroid Carcinoma. Journal of Korean Medical Science, 27, 1019-1026. http://dx.doi.org/10.3346/jkms.2012.27.9.1019

[15] Capoccetti, F., Criscuoli, B., Rossi, G., Ferretti, F., Manni, C. and Brianzoni, E. (2009) The Effectiveness of 124I PET/CT in Patients with Differentiated Thyroid Cancer. The Quarterly Journal of Nuclear Medicine and Molecular Imaging: Official Publication of the Italian Association of Nuclear Medicine, 53, 536-545.

[16] Freudenberg, L.S., Antoch, G., Frilling, A., Jentzen, W., Rosenbaum, S.J., Kuhl, H., Bockisch, A. and Gorges, R. (2008) Combined Metabolic and Morphologic Imaging in Thyroid Carcinoma Patients with Elevated Serum Thyroglobulin and Negative Cervical Ultrasonography: Role of 124I-PET/CT and FDG-PET. European Journal of Nuclear Medicine and Molecular Imaging, 35, 950-957. http://dx.doi.org/10.1007/s00259-007-0634-8

[17] Lubberink, M., Abdul Fatah, S., Brans, B., Hoekstra, O.S. and Teule, G.J. (2008) The Role of (124)I-PET in Diagnosis and Treatment of Thyroid Carcinoma. The Quarterly Journal of Nuclear Medicine and Molecular Imaging: Official Publication of the Italian Association of Nuclear Medicine, 52, 30-36.

[18] Freudenberg, L.S., Jentzen, W., Muller, S.P. and Bockisch, A. (2008) Disseminated Iodine-Avid Lung Metastases in Differentiated Thyroid Cancer: A Challenge to 124I PET. European Journal of Nuclear Medicine and Molecular Imaging, 35, 502-508. http://dx.doi.org/10.1007/s00259-007-0601-4

[19] Erdi, Y.E., Macapinlac, H., Larson, S.M., Erdi, A.K., Yeung, H., Furhang, E.E. and Humm, J.L. (1999) Radiation Dose Assessment for I-131 Therapy of Thyroid Cancer Using I-124 PET Imaging. Clinical Positron Imaging, 2, 41-46. http://dx.doi.org/10.1016/S1095-0397(99)00004-7

[20] Sgouros, G., Kolbert, K.S., Sheikh, A., Pentlow, K.S., Mun, E.F., Barth, A., Robbins, R.J. and Larson, S.M. (2004) Patient-Specific Dosimetry for 131I Thyroid Cancer Therapy Using 124I PET and 3-Dimensional-Internal Dosimetry (3D-ID) Software. Journal of Nuclear Medicine, 45, 1366-1372.

[21] Freudenberg, L.S., Jentzen, W., Gorges, R., Petrich, T., Marlowe, R.J., Knust, J. and Bockisch, A. (2007) 124I-PET Dosimetry in Advanced Differentiated Thyroid Cancer: Therapeutic Impact. Nuklearmedizin, 46, 121-128. 
Scientific Research Publishing (SCIRP) is one of the largest Open Access journal publishers. It is currently publishing more than 200 open access, online, peer-reviewed journals covering a wide range of academic disciplines. SCIRP serves the worldwide academic communities and contributes to the progress and application of science with its publication.

Other selected journals from SCIRP are listed as below. Submit your manuscript to us via either submit@scirp.org or Online Submission Portal.
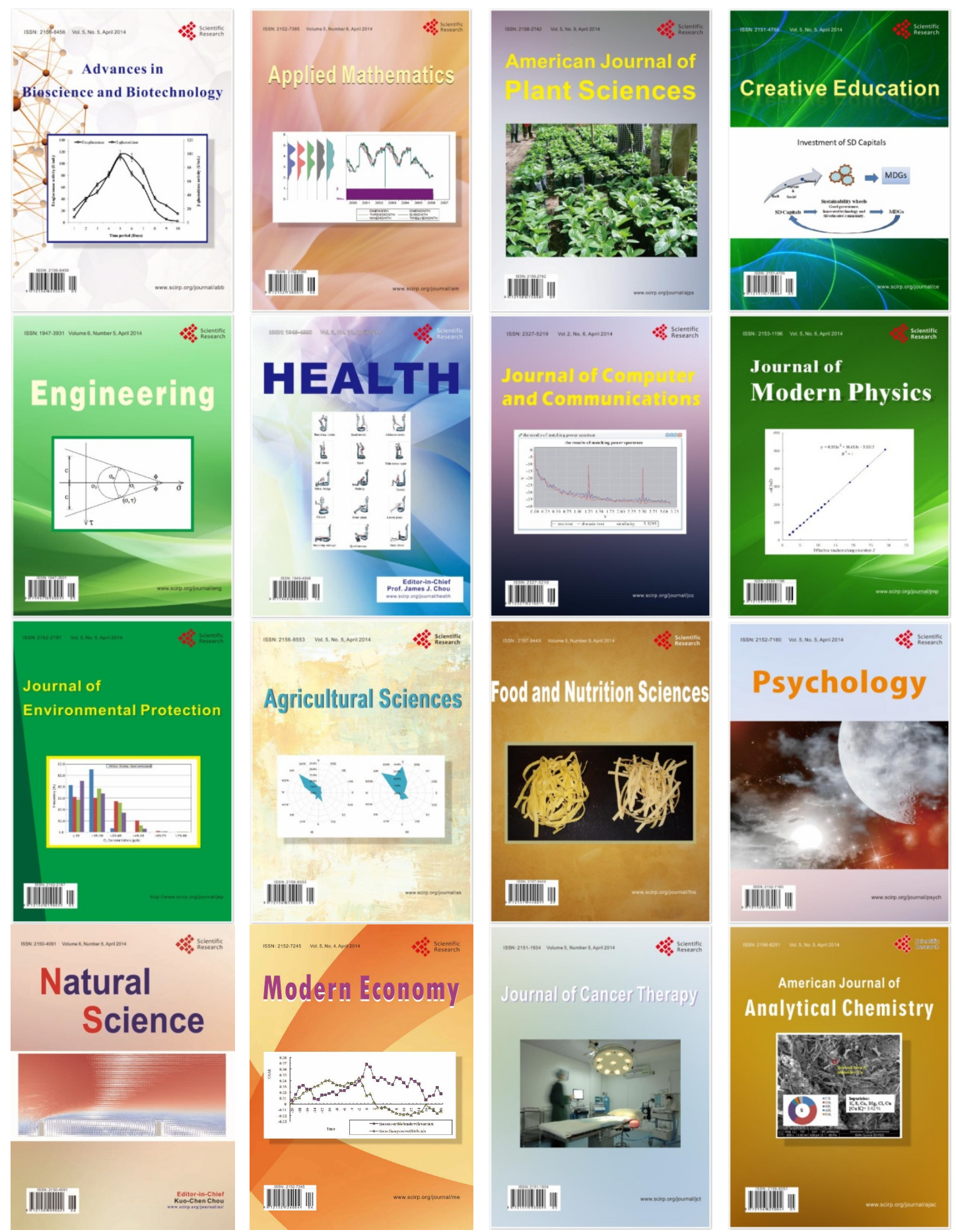